\title{
INDÍGENAS NA EDUCAÇÃO SUPERIOR E POSSIBILIDADES DE DIÁLOGO INTERCULTURAL \\ A EXPERIÊNCIA DO PROGRAMA REDE DE SABERES - MS/BRASIL
}

\author{
INDÍGENAS EN LA EDUCACIÓN SUPERIOR Y POSIBILIDADES DE DIÁLOGO \\ INTERCULTURAL. LA EXPERIENCIA DEL PROGRAMA RED DE SABERES- MS/BRASIL
} INDIGENOUS IN HIGHER EDUCATION AND INTERCULTURAL POSSIBILITIES OF
DIALOGUE. THE EXPERIENCE OF THE RED DE SABERES PROGRAM-MS/BRAZIL

Antonio Hilario Aguilera Urquiza ${ }^{1}$

Fecha de recepción: 24-06-2016

Fecha de aceptación y versión final: 24-10-2016

Resumo: O presente texto pretende aprofundar a reflexão conceitual e epistemológica acerca da possibilidade de diálogo entre os conhecimentos tradicionais e os conhecimentos considerados "Ocidentais", a partir do impacto na vida de indígenas nas universidades públicas no Estado Mato Grosso do Sul (Brasil). Esta região possui a maior quantidade de indígenas cursando a educação superior do país, ao redor de 900 estudantes. A presença dos povos indígenas na educação superior poderia ser compreendida como una estratégia de luta para construir seus processos de autonomia? Indígenas e Universidades, uma relação de colonialidade ou possibilidade de construção de autodeterminação destes povos?

Este texto é fruto de pesquisa em andamento com os seguintes procedimentos metodológicos: inicialmente a investigação documental e bibliográfica, na tentativa de ler as experiências indígenas à luz de alguns autores e teóricos como Hall (2000), Bhabha (2003), Mignolo (2003), Freire (1970; 1992), Quijano (1992), Mato (2008; 2014; 2015), Aguilera Urquiza e Nascimento (2013) seguida pela experiência de trabalho de campo, realizada através de entrevistas semiestruturadas com estudantes indígenas participantes do "Programa Rede de Saberes - permanência de indígenas na educação superior", especialmente com os egressos, aqueles que já terminaram a graduação.

Palavras-chave: colonialidade; indígenas e educação superior; interculturalidade; diálogo de conhecimentos.

Resumen: El presente texto pretende profundizar una reflexión conceptual y epistemológica acerca de la posibilidad de diálogo entre los conocimientos tradicionales y los conocimientos considerados "Occidentales", a partir del impacto en la trayectoria de vida de indígenas que estudian en las universidades públicas del Estado Mato Grosso do Sul (Brasil). Esta región posee la mayor cantidad de indígenas cursando educación superior del país, alrededor de 900 estudiantes. ¿La presencia de pueblos indígenas en la educación superior puede ser comprendida como una estrategia de lucha para construir sus procesos de autonomía? ¿Indígenas y Universidades, una relación de colonialidad o posibilidad de construcción de autodeterminación de estos pueblos?

\footnotetext{
${ }^{1}$ Doctor en Antropología por la Universidad de Salamanca (España). Profesor Adjunto de la Universidad Federal de Mato Grosso do Sul y del Programa de Posgrado en Derechos Humanos (FADIR/UFMS). Coordinador del Programa Red de Saberes desde 2012.Correo electrónico: hilarioaguilera@gmail.com
} 
Este texto es fruto de una investigación en curso con los siguientes procedimientos metodológicos: inicialmente, documental e bibliográfica, con la intención de entender las experiencias indígenas a la luz de algunos autores y teóricos como Hall (2000), Bhabha (2003), Mignolo (2003), Freire (1970; 1992), Quijano (1992), Mato (2008; 2014; 2015), Aguilera Urquiza e Nascimento (2013); seguido por la experiencia de trabajo de campo, realizado a través de entrevistas semiestructuradas con estudiantes indígenas participantes del "Programa Red de Saberes - permanencia de indígenas en la educación superior", especialmente con los egresados.

Palabras-clave: colonialidad; indígenas y educación superior; interculturalidad; diálogo de conocimientos

Abstract: This paper aims to deepen the conceptual and epistemological reflection about the dialogue between traditional knowledge and knowledge considered "Western", in the context of indigenous in public universities in the state Mato Grosso do Sul (Brazil). This area has the largest number of indigenous pursuing higher education of the country, around 900 students. Could be the frequency of indigenous in higher education be understood as a strategy of struggle to build their autonomy processes? Could be understood indigenous and universities relation as a coloniality relationship or the possibility of building self-determination of these people?

This paper is the result of a research in progress, with the following methodological procedures: first, the documentary and bibliographic research, intending to read the student experiences by some authors and theorists such as Hall (2000), Bhabha (2003), Mignolo (2003), Freire (1970; 1992), Quijano (1992), Mato $(2008 ; 2014 ; 2015)$, Aguilera Urquiza e Nascimento (2013), followed by fieldwork experience, performed by semi-structured interviews with indigenous students who compose the "Programa Rede de Saberes- permanência de indígenas na educação superior", in particular those who have completed graduation.

Key words: coloniality; indigenous and higher education; interculturalism; dialogue of knowledge.

\section{Considerações iniciais}

Este texto é fruto da experiência do autor na convivência com indígenas no ensino superior em especial, na implantação e posterior coordenação do programa Rede de Saberes' - permanência de indígenas no ensino superior, um projeto apoiado financeiramente pela Fundação Ford. A partir desta experiência pretende aprofundar a reflexão conceitual e epistemológica acerca da possibilidade de diálogo entre os conhecimentos tradicionais e os conhecimentos considerados "Ocidentais", a partir do impacto na vida de indígenas nas universidades públicas no Estado Mato Grosso do Sul (Brasil), marcada atualmente por alto nível de conflito entre indígenas e proprietários rurais, pela posse da terra.

Como sabemos, esta região possui a maior população indígena do Brasili e, por circunstâncias do contato e proximidade dos centros urbanos, conta atualmente com a maior quantidade de indígenas cursando a educação superior do país, ao redor de 900 estudantes. A tendência é que a cada ano aumente este quantitativo de acesso de indígenas nas universidades, situação que provoca muitas reflexões e questionamentos. A presença dos povos indígenas na educação superior poderia ser compreendida como una estratégia de luta para construir seus processos de autonomia? Como entender ou detectar sinais de diálogos epistêmicos, entre formas diferentes de conhecimentos? Este diálogo é possível?

Ainda podemos perguntar se a relação entre Indígenas e Universidades, configura-se como uma relação de colonialidade ou possibilidade de construção de autodeterminação destes povos. A partir destes questionamentos e do contexto 
regional de Mato Grosso do Sul, este texto foi construído como fruto de pesquisa em andamento com os seguintes procedimentos metodológicos: inicialmente a investigação documental e bibliográfica, na tentativa de ler as experiências indígenas à luz de alguns autores e teóricos como Hall (2000), Bhabha (2003), Mignolo (2003), Freire (1970; 1992), Quijano (1992), Mato (2008; 2014; 2015), Aguilera Urquiza e Nascimento (2013) seguida pela experiência de trabalho de campo, realizada através de entrevistas semiestruturadas com estudantes indígenas participantes do "Programa Rede de Saberes - permanência de indígenas na educação superior", especialmente com os egressos, aqueles que já terminaram a graduação.

Pretendemos, na sequência, apresentar a experiência de dez anos desse Programa, seus avanços e questionamentos e, também, a reflexão epistêmica acerca da possibilidade e efetividade do diálogo entre diversas formas de conhecimento e saberes.

\section{O Programa Rede de Saberes e o contexto regional ${ }^{\mathrm{iii}}$}

Esses jovens indígenas que cada vez mais demandam por acesso às universidades são originários de povos que, em geral, enfrentaram e enfrentam uma longa e histórica luta contra a exclusão e o preconceito, fato que marca a sua relação com o entorno regional. É nesse contexto que iremos refletir sobre os indígenas e o ensino superior no Estado de Mato Grosso do Sul: as lutas por autonomia, os processos de adaptação, a construção de políticas de sustentabilidade e as relações interétnicas no interior desses novos espaços.

As Instituições de Ensino Superior (IES) no Estado também refletem e têm contribuído para a reprodução de um quadro regional de exclusão e discriminação dos indígenas. Por outro lado, nessas mesmas instituições existem projetos e atividades, como as Licenciaturas Indígenas ${ }^{\mathrm{iv}}$ e o Programa Rede de Saberes, que tem contribuído para respostas parciais a algumas demandas importantes dos acadêmicos indígenas nos últimos anos. Esses apoios, embora limitados, são percebidos pelos próprios acadêmicos indígenas como de grande relevância política porque, somados ao seu empenho pessoal e coletivo, têm permitido resultados significativos.

Tendo em vista que no Brasil ainda são incipientes as políticas públicas destinadas a atender aos anseios de autonomia dos indígenas, as comunidades destes passam a considerar as universidades que as acolhem (que buscam fazer 0 exercício de acolher a diferença) como um "terceiro espaço", ou seja, ambiente de negociações e reafirmações identitárias, de discussão de projetos de autonomia e, inclusive, de maior visibilidade. As universidades tornam-se, nesse cenário, a possibilidade real de aliados, seja na busca de novas alternativas para a gestão de seus territórios, ou mesmo para a implementação da educação indígena desejada por cada povo.

Muitos/as são os/as indígenas, na atualidade, que passaram pelas universidades, contaram com o apoio do Programa Rede de Saberes, e após terminarem a graduação voltaram para suas aldeias/comunidades e desempenham importantes papeis. Éder Terena foi da primeira turma de acadêmicos atendidos pelo Programa na UCDB; voltou para a aldeia Buriti como professor, fez mestrado em História e hoje, atua como liderança e vereador, representando os interesses da comunidade no 
município de Dois Irmãos do Buriti/MS. Maria de Lourdes, Celinho, Paulo Baltasar e Celma Fialho, todos do povo Terena, receberam apoio do Programa Rede de Saberes, fizeram mestrado e atualmente são importantes líderes da educação indígena em suas aldeias: Paulo Baltasar e Celma Fialho fazem parte da equipe de coordenação da Licenciatura que forma professores indígenas, na UFMS de Aquidauana/MS, enquanto Maria de Lourdes e Celinho são os coordenadores da Educação Indígena da Aldeia Cachoeirinha (Miranda/MS). Poderíamos citar, aqui, vários outros exemplos, de indígenas das etnias Ñandeva, Kaiowá (ambos Guarani), Terena, Kadiwéu, Kiniquinau e, inclusive, Bororo e Xavante, que são de Mato Grosso, que passaram pelas universidades e ao voltarem para suas comunidades de origem exercem importantes papeis de lideranças.

$\mathrm{Na}$ percepção de muitas lideranças indígenas do Estado, as universidades podem ser espaços privilegiados para o diálogo e o encontro de culturas, deixando de lado o período em que essas mesmas instituições eram consideradas âmbitos de reprodução da exclusão e do preconceito contra os povos indígenas. Nesse sentido, o acesso ao ensino superior pode servir como ferramenta para superar as tentativas/tendências do Estado brasileiro para a homogeneização das práticas culturais, visando, assim, incentivar processos de autonomia regional e políticas de sustentabilidade dos povos indígenas.

Nesse sentido podemos dizer, conforme Brand e Nascimento (2008, p. 127), que:

Sob a ótica dos povos indígenas, as experiências em andamento confirmam que a educação superior pode contribuir, significativamente, para criar melhores condições de sustentabilidade e autonomia das populações indígenas no Brasil. Exige, porém, das Universidades, repensarem suas metodologias de ensino e questionamento do saber historicamente sedimentado, a partir da visão de mundo ocidental.

Ao ampliar e fortalecer a presença dos acadêmicos indígenas em cada instituição universitária, estimulando a sua participação em todas as atividades acadêmicas e de extensão, desenvolvidas no âmbito das mesmas instituições, esses projetos e ações abrem brechas importantes, especialmente na perspectiva do diálogo de saberes, superando e indo além, inclusive, da limitada, embora socialmente relevante, perspectiva da inclusão, sinalizado pelas políticas de cotas (Brand; Nascimento, 2008, p. 127).

Em uma perspectiva histórico-processual, podemos afirmar que em todo o CentroOeste, mas de modo particular no Estado de Mato Grosso do Sul, os povos indígenas estiveram e estão no meio do caminho da política expansionista do Estado Brasileiro, que se concretizou, inicialmente, através da violenta expansão da frente de colonização, conhecida como "marcha para o oeste".

Nestes anos recentes foi muito violento o processo de avanço das frentes de colonização, tendo como consequência imediata a perda, por parte dos povos indígenas, de seus territórios tradicionais. Foram várias ondas de ocupação desta região, incentivados pelo governo federal: após a Guerra da Tríplice Aliança (conhecida como Guerra do Paraguai) veio a instalação da Cia Matte Laranjeira, ocupando o território do povo Guarani e utilizando sua mão de obra de forma compulsória na exploração da erva mate; em seguida, na primeira metade do século 
XX, com a criação da CAND (Colônia Agrícola de Dourados) em 1943, a repartição e venda (titulação) de parte das terras indígenas para os colonos, com predomínio da agricultura e pecuária; na segunda metade do século XX, a invasão das monoculturas para exportação: inicialmente a soja e depois a cana, para a produção de álcool e açúcar.

Já mais recentemente, na década de 1970, os povos indígenas se confrontaram com a monocultura da soja e consequente mecanização da atividade agrícola. E, nesse momento, com a expansão dos canaviais, que vão cercando aldeias e casas. Nesse processo, o comprometimento dos recursos naturais, resultante da perda da terra, retirou as condições necessárias para o exercício da economia tradicional, impondo aos homens indígenas o assalariamento. Provocou a rápida passagem de alternativas variadas de subsistência - agricultura, caça, pesca e coleta - para uma única alternativa, a agricultura, e esta apoiada em poucas variedades de cultivos, e, mais recentemente, o assalariamento em usinas de álcool e açúcar, ou na coleta da maça, no sul do país ${ }^{\text {vi; }}$ situação que tende a mudar nos próximos anos, com a mecanização do corte de cana, jogando, por outro lado, milhares de indígenas para a informalidade. No entanto, mais do que as alternativas econômicas, essa situação vai comprometendo, de forma crescente, a autonomia interna desses povos por reduzir suas possibilidades de decisão sobre essas questões, deixando cada vez um espaço mais reduzido para a negociação a partir de suas alternativas histórico-culturais.

Esta breve síntese histórica demonstra o grau da expropriação de seus territórios sofrida pelos povos indígenas no sul de Mato Grosso do Sul. Na atualidade temos um estado de grandes propriedades e os povos indígenas vivendo em pequenas parcelas de seu território tradicional, em situação de confinamento ${ }^{\text {vii. }}$.

Com a redução de seus territórios, tornou-se muito difícil a reprodução física e cultural destes povos. Talvez por isso, vejam a educação como uma das janelas abertas para reequilibrar as relações assimétricas com 0 mundo capitalista/colonizador. É nesse contexto que essas populações vêm buscando, de forma crescente, o ensino escolar básico e, mais recentemente, aumenta a demanda pelo acesso ao Ensino Superior nas Universidades, como ferramenta que pode ajudálos a enfrentar o futuro incerto. Nos últimos anos muitos jovens indígenas têm entrado nas universidades, porém, muitos também têm saído sem terminar seus cursos de graduação (e segue forte o preconceito de que "eles saem porque são incapazes"). Claro que muitos também conseguem terminar seus cursos, com muita dificuldade e alguns, inclusive, chegam a fazer a pós-graduação. No entanto, mesmo com as políticas atuais de ingresso e permanência, muitos indígenas não conseguem terminar a graduação.

O número de ingresso é crescente, mas o número de evasão dos estudantes indígenas é constante, ainda que com algumas variações, dependendo do período e da universidade. No início do século XXI, mais da metade dos estudantes indígenas deixavam a universidade sem terminar a graduação. Percebemos, que a partir da criação do Programa Rede de Saberes, esta evasão diminuiu consideravelmente, porém, permanece uma taxa de desistência acima de 35\% para estudantes indígenas que ingressam em cursos regulares. Aqueles que entram para estudar a Licenciatura específica, tem um resultado bem diferente: ao redor de $90 \%$ terminam seus cursos, o 
que demonstra o quanto a Universidade deve se adequar epistemologicamente às culturas e conhecimentos dos povos indígenas.

Apesar de todo este contexto histórico contrário aos povos indígenas, Mato Grosso do Sul é o estado brasileiro que mais possui jovens indígenas na educação superior, ao redor de 900 alunos, em especial, nas três universidades públicas (UFMS, UFGD e UEMS) e na católica (UCDB). Cremos que esta situação ocorre, também, porque para eles, a educação superior pode ser considerada como uma ferramenta de negociação com o mundo do "branco", e fundamental para a construção de sua autodeterminação e propostas de futuro.

Dessa forma, estudar este processo de apropriação, pelos indígenas, dos espaços da educação superior, e as formas de diálogo intercultural entre os conhecimentos tradicionais e os chamados conhecimentos "Ocidentais", tem grande relevância, sobretudo para os próprios povos indígenas e para o avanço da compreensão, na academia, de como ocorrem as tentativas de revisão epistemológica da educação superior no Brasil.

\section{Rede de Saberes - autonomia e diálogo possível?}

Neste contexto de rápidas mudanças sociais e políticas e após a Constituição Federal de 1988, a qual reconhece em seu artigo 231 o respeito à cultura, tradição e territórios tradicionalmente ocupados, as universidades começam a receber mais e mais indígenas. Em 2004, com o apoio do LACED (Laboratório de Pesquisas em Etnicidade, Cultura e Desenvolvimento) da UFRJ (Universidade Federal do Rio de Janeiro) e apoio financeiro da Fundação Ford, começam as negociações para a construção do Programa Rede de Saberes. Inicialmente as tratativas ocorrem entre duas universidades: Universidade Católica Dom Bosco (UCDB) - comunitáriaparticular; e Universidade Estadual de Mato Grosso do Sul (UEMS) - pública-estadual. Logo depois, a partir de 2007, juntaram-se outras duas públicas: Universidade Federal de Mato Grosso do Sul (UFMS) e Universidade Federal da Grande Dourados (UFGD).

Entendemos que o que se busca, na verdade, com o acesso à educação superior, é a questão da autonomia dos povos indígenas, e a educação mostra-se como uma das possibilidades dessa conquista. Por outro lado, é importante ressaltar que esse dinâmico e às vezes contraditório processo de busca de autonomia, presente nas lutas e ações coletivas, é protagonizado por povos que eram, historicamente, autônomos, desenvolvendo para isso complexas e variadas relações de troca, de aliança ou mesmo de guerra com os outros povos. No presente, a afirmação da autonomia de cada povo continua relacionada diretamente às possibilidades (e a dos povos indígenas em geral) em alterar as relações, historicamente e estabelecidas com o entorno regional. E, nesse sentido, essa população segue recorrendo a complexas e variadas relações de negociação e tradução viii, processos nem sempre perceptíveis aos atores sociais. E aí, o espaço escolar/universitário vem se constituindo como lugar privilegiado para a dinamização e compreensão desses processos.

É sob o prisma da autonomia que se articulam e criam sentido, de um lado, as grandes lutas pela necessária ampliação territorial e, de outro, as demandas por um ensino específico e de qualidade, incluindo o acesso à Universidade, a busca de 
participação nos espaços de representação e decisão da sociedade não indígena, como os poderes legislativos e executivos, entre outros (Brand, 2006).

Nesse sentido, a educação vem se constituindo em demanda importante na luta pelos direitos dos povos indígenas no Brasil e, em particular, no Mato Grosso do Sul. A partir das práticas concretas de educação indígena nas últimas décadas, já é possível perceber a influência da visão culturalmente diferenciada desses povos, a força que suas práticas rituais e míticas exercem, influenciando, de certo modo, até mesmo as propostas curriculares das escolas nas aldeias e, inclusive experiências incipientes em algumas universidades, como ocorre, por exemplo, nas licenciaturas específicas (UFGD e UFMS) e até mesmo na pós-graduação em Educação da UCDB, com marcante presença de indígenas. Assim, o respeito às formas de pedagogia endógenas (processos próprios de aprendizagem), o uso dos seus idiomas, a formação e capacitação de professores indígenas e até mesmo a elaboração de materiais didáticos culturalmente aceitáveis, são algumas das bandeiras dos estudantes e organizações indígenas para as universidades.

Entretanto, estar na universidade, faz surgir alguns problemas, ou desafios, como por exemplo, as dificuldades em dialogar com esses povos, situados em outra tradição cultural, com saberes e processos sociais e históricos diferenciados. Nesse sentido, podemos elencar as questões relacionadas a práticas de discriminação (funcionários, colegas que evitam participar de grupos de estudos/trabalhos com acadêmicos indígenas), dificuldades de compreensão dos códigos acadêmicos (linguagem, leitura e compreensão de textos, expressão oral), burocracia acadêmica (documentos, prazos), entre outros.

Dessa forma, quando chegam ao espaço da educação superior, estes mesmos indígenas, em sua quase totalidade, oriundos de aldeias tradicionais, encontram uma barreira epistémica quase intransponível, sobretudo pela dificuldade do reconhecimento de seus conhecimentos (cf. AGUILERA URQUIZA; NASCIMENTO, 2013). As universidades, em seus currículos e nas próprias metodologias de ensino não reconhecem, ou desvalorizam completamente 0 que chamamos de conhecimentos tradicionais. Assim, a partir deste contexto, que é a chegada massiva de indígenas na Educação Superior, queremos aprofundar a discussão teórico-prática das experiências do programa Rede de Saberes e a possibilidade de diálogo entre os conhecimentos tradicionais indígenas e os chamados "conhecimentos Ocidentais". Em outras palavras, uma reflexão teórica acerca da possibilidade de um diálogo intercultural no contexto das universidades dos povos indígenas.

Para além das propostas do multiculturalismo, as características que assume atualmente a educação intercultural entendida tanto a nível normativo e de políticas educativas, assim como modalidade particular e diferenciada dentro dos sistemas educativos nacionais, impulsionam para praticas formativas e conhecimentos produzidos em diferentes âmbitos da vida social e familiar dos povos tradicionais, em especial entre os povos indígenas. Como sabemos, os conhecimentos indígenas vêm se desenvolvendo ao longo do tempo em sucessivas gerações, e nos tempos atuais se relacionam, de certa maneira, com a constituição e extensão dos sistemas públicos de instrução nas universidades. Acreditamos, assim, que optar pela proposta de uma educação intercultural tem a ver com a luta pelo direito à diferença, na convivência social, pois no caso dos indígenas, são povos oriundos de outra tradição/matriz 
cultural que não a eurocêntrica, Ocidental, e por isso, buscam o "reconhecimento de seus conhecimentos tradicionais", também no âmbito da universidade.

Por outro lado, atentos ao fato de que estas modalidades de educação intercultural estão atravessadas pela tensão entre ser resposta à demanda de reconhecimento da diversidade e contribuir para a fragmentação e a desigualdade educativa, questionamos os alcances e limites das propostas de inclusão social nas universidades em sua articulação com o reconhecimento dos particularismos étniconacionais. Não basta para estes povos tradicionais chegar à universidade, pois este pode tornar-se - se já não o é - um espaço de epistemicídio, conceito desenvolvido por Boaventura de Sousa Santos (2010).

Atualmente, no Brasil, há políticas de reservas de vagas para indígenas nas universidades federais, assim como há políticas de bolsas especiais para estudantes indígenas na educação superior. No entanto, não se toca no eixo duro das concepções epistemológicas dos conhecimentos chamados de "universal", eurocêntrico, hegemônico em grande parte destas instituições. Nos últimos anos, por força de um ordenamento jurídico favorável, as universidades têm buscado adaptarem-se a estes novos atores sociais, porém, de maneira geral, com mudanças superficiais, como por exemplo, providenciar acessibilidade aos que andam com cadeiras de roda. Muito poucas, porém, querem mudar as concepções hegemônicas das universidades. Neste sentido, algumas universidades de Mato Grosso do Sul, conforme afirmado anteriormente, no âmbito do Programa Rede de Saberes, tentam ensaiar a discussão do "diálogo de saberes", ou seja, ir além da inclusão de indígenas, mas procurando abrir espaços para seus conhecimentos tradicionais.

Para compreender esta relação entre distintas matrizes de conhecimento, a partir e um contexto de colonialidade, se faz necessário desenvolver uma análise crítica, epistemológica e intercultural, e para isso, torna-se fundamental propor 0 reconhecimento das culturas e conhecimentos tradicionais, assim como reconhecer a autodeterminação dos povos indígenas, conforme assegurado no atual ordenamento jurídico internacional (Convenção 169 da OIT). Mesmo assim, sabemos das ambivalências e desafios postos a esta questão. Entendemos ambivalência na perspectiva de Bhabha (2003), quando se refere ao mito da unidade cultural, a quem chama de "mito progressista da modernidade", ou "mitos totalizadores". A proposta do conceito de "ambivalência" é distinta de duplicidade. Para Bhabha (2003, p.144), as pessoas ambivalentes "olham em duas direções sem precisar ter duas caras".

Seguindo Quijano (1992) e Mignolo (2003), propomos inicialmente uma crítica cultural às configurações históricas do imaginário do sistema colonial/moderno, fundamentado na colonialidade do poder e do saber, e na diferença colonial que historicamente produz una geopolítica do conhecimento que torna subalternos os conhecimentos e culturas dos povos tradicionais, em especial os indígenas. Dentro desta perspectiva, uma proposta de investigação mais abrangente poderá identificar os processos de subalternização das diferentes formas de conhecimentos, memórias, línguas e histórias locais, suprimidas e silenciadas pela colonialidade do poder no imaginário moderno e colonial destes estudantes indígenas.

Ao chegarem aos espaços da chamada "academia", muitos destes indígenas carregam consigo séculos de opressão e negação de suas culturas e de suas formas próprias de conhecimentos e saberes. Muitos, inclusive - fruto deste movimento 
colonial e que segue gerando colonialidade - chegam a almejar os conhecimentos que chamam "do branco", negando em movimento ambivalente, aos seus próprios conhecimentos oriundos de seus ancestrais.

Dessa forma, além da questão das representações sobre os povos indígenas, é necessário ampliar a reflexão acerca dos conhecimentos que estes povos trazem para as universidades, na tentativa de quebrar a hegemonia de uma única episteme. É importante, ainda, pensar sobre qual lugar estes conhecimentos tradicionais indígenas encontram no diálogo entre conhecimentos institucionalizados no interior das universidades, se é que ocupam algum lugar.

Os escritos de alguns autores chamados pós-coloniais ${ }^{\mathrm{ix}}$, como Quijano (1992), Bhabha (2003) e Mignolo (2003) são caracterizados por reflexões acerca da possibilidade de análise sobre nossas lógicas epistêmicas e possuem como uma de suas preocupações centrais a história dos povos colonizados. Criticam os processos e os discursos que (re) produzem representações desses povos com o objetivo de deslocar a visão etnocêntrica que herdamos com a colonização. Como sabemos, o prefixo "pós" na expressão pós-colonial não indica simplesmente um "depois" no sentido cronológico linear; trata- se de uma operação de reconfiguração do campo discursivo, no qual as relações hierárquicas ganham significado. Colonial, por sua vez, vai além do colonialismo e alude a situações de opressão diversas, definidas a partir de fronteiras de gênero, étnicas ou raciais (COSTA, 2006, p. 117-118).

Retomamos aqui a questão apresentada no início: A presença dos povos indígenas na educação superior poderia ser compreendida como una estratégia de luta para construir seus processos de autodeterminação? A resposta a esta importante questão, seria, de certo modo, a hipótese de nossa pesquisa, afinal, a Universidade, da forma como a conhecemos, é uma "invenção" do Ocidente eurocêntrico e está sendo assumida e ressignificada pelos povos indígenas no Brasil e na América Latina. A partir do conceito de cultura de Hall $(1997,2003)$ e, sobretudo, considerando os estudos de Freire $(1970,1992)$, podemos dizer que a Universidade historicamente representou a "cultura dominante", hegemônica e que os empobrecidos sempre tiveram muitas dificuldades em acessá-la.

Entretanto, a partir de conversas preliminares (entrevistas e observações) e a partir da convivência e experiência de mais de dez anos com o Programa Rede de Saberes, é possível afirmar que a universidade, sobretudo e há mais tempo para o povo Terena, tem sido compreendida como uma estratégia de empoderamento, de adquirir/dominar as "ferramentas do branco", como dizem, assim como ocorre com a maior parte, que volta para a aldeia para formar as novas gerações. No início os cursos de graduação mais procurados eram as licenciaturas (pedagogia, história, matemática, etc.), com foco na formação de professores. $\mathrm{Na}$ atualidade aumenta a procura por outros cursos: direito, agronomia, enfermagem, dentre outros; profissões que poderão contribuir ainda mais para a autonomia destes povos.

A "cultura" do "oprimido" quase nunca teve lugar nos currículos e espaços universitários. Neste contexto, retomamos os estudos de Mato (2008, 2009, 2010), acerca da presença de indígenas nas universidades latino-americanas, nas quais vemos vários modelos de presença: universidades tradicionais, universidades interculturais e as universidades indígenas. Explicita, ainda, o autor, o conceito de interculturalidade com equidade (Mato, 2011), ou seja, o respeito à diversidade 
sociocultural e a possibilidade do diálogo epistemológico, quando tratamos dos conhecimentos. Segundo Mato (2011, p. 65), estes povos lutam por:

\begin{abstract}
Reformas legales, incluso constitucionales, que tiendan a hacer posible la materialización de esa consigna, comenzando por lograr el reconocimiento del carácter pluriétnico de los respectivos Estados nacionales, así como la existencia de formas de ciudadanía culturalmente diferenciadas, que algunos denominan "ciudadanía cultural", que pienso que también podríamos denominar de "ciudadanía con equidad".
\end{abstract}

Dessa forma, podemos afirmar que os povos indígenas lutam não apenas por uma universidade intercultural, que reconheça os conhecimentos tradicionais, mas lutam também por um Estado Nacional que se reconheça multiétnico seguido da exigência do que chamamos de uma cidadania cultural com equidade e, em especial, a luta pela autonomia de suas comunidades e gestão de seus territórios tradicionais. Todos estes elementos podem ser compreendidos como uma estratégia de luta para construir seus processos de autodeterminação, sendo o acesso à universidade um destes elementos, talvez a porta privilegiada que ajuda a abrir outros caminhos para quebrar a assimetria nas relações de poder nas sociedades atuais.

\title{
Considerações Finais
}

As demandas dos povos indígenas por ensino superior refletem, claramente, as contingências da experiência histórica vivida. Buscam fortalecer os seus conhecimentos tradicionais, sua história e língua e, ao mesmo tempo, o necessário domínio dos assim denominados conhecimentos universais, considerados necessários para uma melhor inserção no entorno regional, e relevante para os seus projetos de autonomia.

O risco é que as Universidades, em seus projetos de ensino superior para os povos indígenas, sigam passando ao largo dos processos mais amplos de busca de autonomia das populações indígenas e centrem sua preocupação apenas em permitir o acesso dos índios aos seus ambientes acadêmicos, o que é, certamente, muito pouco ${ }^{x}$. Dessa forma, destacamos o conceito de autonomia, entendido, aqui, conforme Brand (1999), no contexto da Constituição de 1988, na qual se encontra uma série de dispositivos relacionados ao reconhecimento desse direito. Destacam-se, entre esses dispositivos, o reconhecimento da organização social, costumes, línguas, crenças e direitos originários sobre as terras que tradicionalmente são ocupadas pelos povos indígenas. Ao reconhecer e determinar o respeito à organização social e às terras de cada povo, o texto constitucional restringe a ação do Estado à garantia desses direitos.

Nesse contexto se encontram, também, os limites legais da autonomia dos povos indígenas. Evidentemente que cada povo interpretará e atribuirá dimensões específicas ao termo em epígrafe, em função de sua cultura e de sua experiência histórica de enfrentamento do entorno regional, donde decorrem em grande parte, hoje, suas expectativas de futuro. Entendemos, assim, por entorno regional, aqueles setores da sociedade nacional que se situam e/ou têm interesses específicos junto às 
comunidades indígenas ou, ainda, que são objeto de interesse por parte das mesmas comunidades. Incluem-se aqui órgãos públicos, igrejas, mídia, proprietários residentes nesse entorno e outros.

Não se trata, portanto, de um conceito geográfico, mas relacional. O conceito de autonomia é, hoje, para os povos indígenas, um conceito em construção e diretamente relacionado à luta de cada um deles. A sua abrangência concreta depende exatamente da ampliação das perspectivas históricas de luta de cada povo. Por isso a compreensão do conceito nos remete para o necessário estudo de sua cultura, de sua história e das perspectivas frente ao entorno regional.

É importante salientar que esse processo de construção de autonomia passa, inevitavelmente, pela questão dos territórios, entendidos como construção resultante do "esforço coletivo de um grupo social para ocupar, usar, controlar e se identificar" com determinada parcela do ambiente físico. Remete, portanto, para as situações e "contingências históricas", vivenciadas pelos povos indígenas.

É nesse contexto que se insere o acesso dos povos indígenas ao ensino superior. Como, no entanto, ir além desse simples acesso às universidades, reconhecendo que se trata de povos situados em outra tradição cultural, com saberes e processos sociais e históricos diferenciados? Como transitar em direção a uma educação mais engajada nos problemas diários vivenciados pelos povos indígenas, nos quais se destacam problemas relacionados aos seus territórios, recursos naturais e à reconstrução de condições de sustentabilidade, ou, ainda, problemas decorrentes de relações profundamente assimétricas, marcadas e corroídas pelo preconceito contra seu modo de vida? Podemos afirmar, neste sentido, que após mais de dez anos de atividades, o Programa Rede de Saberes adquiriu bastante bagagem e experiências interessantes que podem responder a esses questionamentos: a maior parte destes egressos indígenas retornou a suas respectivas aldeias, atuando como professores ou em outras funções importantes: ex-alunos na política, como o vereador Eder Alcântara Oliveira; pedagogas como a mestra em Educação Karina, de mãe Kadiwéu; advogado como o Luis Eloy Amado, Terena, que advoga a favor dos povos indígenas do estado; outros tantos continuaram seus estudos, cursando o mestrado e alguns até mesmo 0 doutorado. Todos eles demonstram que responderam às oportunidades e que mesmo a partir de ações pontuais favoráveis aos indígenas nas universidades, foi o suficiente para dar respostas positivas. No entanto, essas respostas não evitam a tendência hegemônica de desrespeito às diferenças culturais e indiferença aos conhecimentos indígenas no ensino superior.

Como transformar, nesse contexto, o espaço escolar, em especial o acadêmico, em espaço de trânsito, troca e articulação de saberes e alternativas em uma população que se confronta com inúmeros desafios novos?

\section{Bibliografía}

Aguilera Urquiza, A. H.; Nascimento. REDE DE SABERES - Políticas de Ação Afirmativa no Ensino Superior para indígenas no Mato Grosso do Sul. 01. ed. Rio de Janeiro: FLACSO, GEA; UERJ, LPP, 2013. v. 01. 86p. 
; Landa, B. S; Ferreira, E. M. L; Vianna, F. L. B. Indígenas no ensino superior: as experiências do programa Rede de Saberes, em Mato Grosso do Sul. 01. ed. Rio de Janeiro: E-papers, 2014. v. 01. 192p.

Aguilera Urquiza, A. H; Nascimento, A. C; Espíndola, M. A. J. Jovens indígenas e o ensino superior em Mato Grosso do Sul: desafios e perspectivas na busca por autonomia e respeito à diversidade. Tellus, ano 11, n. 20, jan./jun. 2011.

Bhabha, H. O local da cultura. Belo Horizonte: UFMG, 2003.

Brand, Antônio J. O impacto da perda da terra sobre a tradição Kaiowá/Guarani: os difíceis caminhos da Palavra. Tese de doutorado, História da PUC/RS, 1997, $382 \mathrm{p}$.

. Formação de professores indígenas em nível superior. In: Quaestio - Revista de Estudos de Educação, Sorocaba, SP, v. 8, n. 1, p. 73-82, maio 2006.

; Nascimento, Adir C. Os povos indígenas nas instituições de educação superior e os desafios da sustentabilidade e da autonomia. In: Galvão, A. C. T.; Santos, G. L. (Orgs.). Educação: tendências e desafios de um campo em movimento. Brasília, DF: Liber Editora/ANPED, 2008. v. 2.

Costa, Sérgio. Desprovincializando a sociologia: a contribuição pós-colonial. In Revista Brasileira de Ciências Sociais, v. 60, n. 21, p. 117-134, 2006.

Freire, Paulo. Pedagogia do Oprimido. Rio de Janeiro: Paz e Terra. 1970. . Pedagogia da Esperança. Rio de Janeiro: Paz e Terra. 1992.

Hall, Stuart. A centralidade da cultura: notas sobre as revoluções culturais do nosso tempo. Revista Educação e Realidade, Porto Alegre, v.22, n. 2, p.15-46, jul./dez.1997.

Quem precisa da identidade. In: Silva, T.T.; Hall, Stuart; Woodward, Kathryn. Org. Identidade e diferença. A perspectiva dos Estudos Culturais. 6o ed. Petrópolis: Vozes, 2003.

Mato, Daniel. (Org.) Diversidad cultural e interculturalidad en Educación Superior. Experiencias en América Latina. Caracas: UNESCO-IESALC. 2008.

Instituciones Interculturales de Educación Superior en América Latina. Procesos de construcción. Logros, Innovaciones y Desafíos. Caracas: IESALCUNESCO, 2009.

Educación Superior, Colaboración Intercultural y Desarrollo Sostenible/Buen Vivir. Experiencias en América Latina. Caracas: IESALC-UNESCO. 2010.

(Org.) Educación superior y Pueblos Indígenas en América Latina. Buenos Aires: UNTREF. 2014.

Mignolo, W. Histórias Locais/Projetos Globais: Colonialidade, Saberes Subalternos e Pensamento Liminar. Belo Horizonte: Ed. UFMG. 2003.

Quijano, Aníbal. Colonialidad y modernidad/racionalidad. In H. Bonilla (Org.) Los Conquistados. 1942 y la población indígena de las Américas. Quito, Libri Mundi / tercer Mundo Editores. 1992.

Santos, Boaventura de S. Más allá del pensamiento abismal: de las líneas globales a una ecología de saberes. En: Cairo, H. y Grosfoguel, R. (Org.) Descolonizar la modernidad, descolonizar Europa. Madrid: IEPALA, 2010.

\section{Notas:}

\footnotetext{
'REDE DE SABERES - permanência de indígenas no ensino superior. Trata-se de um programa financiado pela Fundação Ford (em nível nacional, inicialmente chamou-se TRILHAS DO CONHECIMENTO, coordenado pelo LACED/Universidade Federal de Rio de Janeiro), e que reúne uma parceria entre as quatro maiores universidades do estado (UCDB, UEMS, UFGD e UFMS), vigente desde final de 2005.
} 
ii Mato Grosso do Sul possui ao redor de 85 mil indígenas (SESAI, 2015), distribuídos em 9 etnias. Os Kaiowá e Ñandeva (dois grupos pertencentes à língua Guarani) com aproximadamente 50 mil pessoas, seguidos pelo povo Terena com cerca de 30 mil e o povo Kadiwéu com 2 mil pessoas. As demais etnias (Atikum, Guató, Ofaié, Kiniquinau e Camba), não chegam a 500 pessoas, com sérias dificuldades de manutenção da língua e sem os territórios tradicionais.

iii Item baseado originalmente em texto publicado de: AGUILERA URQUIZA, A. H; NASCIMENTO, A. C; Espíndola, M. A. J. Jovens indígenas e o ensino superior em Mato Grosso do Sul: desafios e perspectivas na busca por autonomia e respeito à diversidade. Tellus, ano 11, n. 20, jan./jun. 2011.

iv Trata-se, inicialmente, da Licenciatura Guarani (TEKO ARANDU), construída por equipe multidisciplinar e interinstitucional ao longo de vários anos e, tendo como protagonistas do processo, um grupo de representantes dos professores Guarani e Kaiowá de Mato Grosso do Sul, juntamente com a UFGD (Universidade Federal da Grande Dourados) e a UCDB (Universidade Católica Dom Bosco). Mais recentemente, temos a Licenciatura Povos do pantanal que congrega os demais povos indígenas de Mato Grosso do Sul.

' Trata-se de uma política levada a cabo pelo estado brasileiro nas décadas de 1930 e 1940, durante o governo do Presidente Getúlio Vargas, a qual preconizava a ocupação de "espaços vazios" do território nacional, como uma estratégia geopolítica de garantir as fronteiras brasileiras. Para este fim, o governo desconsidera a presença indígena e passa a incentivar a migração massiva de colonos do sul do país (especialmente gaúchos), do Sudeste (Minas Gerais e São Paulo) e do Nordeste.

vi Ao redor de 400 homens, da Área Indígena Te'ýikue de Caarapó, por exemplo, trabalham a maior parte dos meses do ano nas usinas de produção de açúcar e álcool da região, através de contratos de trabalho de 60 dias ou mais, ou mais recentemente, viajando para o sul do Brasil para a coleta de maçã.

vii Confinamento seria o processo histórico de ocupação do território por frentes não-indígenas, que se seguiu à demarcação das reservas indígenas pelo SPI (Serviço de Proteção ao Índio, criado em 1910, como a primeira agência do estado brasileiro destinada a gerir políticas para os povos indígenas), forçando a transferência dessa população para dentro dos espaços definidos pelo Estado como posse indígena. Indica, portanto, o processo de progressiva passagem de um território indígena amplo, fundamental para a viabilização de sua organização social, para espaços exíguos, demarcados a partir de referenciais externos, definidos tendo como perspectiva a integração dessa população, prevendo-se sua progressiva transformação em pequenos produtores ou assalariados a serviço dos empreendimentos econômicos regionais (BRAND, 1997).

viii Ao analisar os processos pós-coloniais, Bhabha (1998) recorre ao conceito de negociação para buscar superar as visões dualistas, que opõem, simplesmente, dominador e dominado, centro-periferia, rico-pobre, branco-negro, entre outros, chamando a atenção para as estruturas de interação, presentes entre os dois, buscando articular elementos antagônicos e opostos, porém, sem a pretensão da sua superação dialética. A negociação sinaliza para um processo que não se identifica com nenhum dos dois polos, mas algo mais que contesta e vai além de ambos.

${ }^{i x}$ Os estudos pós-coloniais não constituem propriamente uma matriz teórica única, mas apresentam como característica comum o esforço de esboçar, pelo método da desconstrução dos essencialismos, uma referência epistemológica crítica às concepções dominantes de modernidade. Iniciada por aqueles autores qualificados como intelectuais da diáspora negra ou migratória a perspectiva pós-colonial teve, primeiro na crítica literária, sobretudo na Inglaterra e nos Estados Unidos, a partir dos anos de 1980, suas áreas pioneiras de difusão. Depois disso, expande-se geograficamente e para outras disciplinas, fazendo dos trabalhos de autores como Homi Bhabha, Edward Said, Gayatri C. Spivak ou Stuart Hall e Paul Gilroy referências recorrentes em outros países dentro e fora da Europa (COSTA 2006, p. 117).

${ }^{x}$ A UnB (Universidade de Brasília),pode ser citada como um exemplo de Universidade que tem apostado em abrir possibilidades de formação para a autonomia e a sustentabilidade. Em 2010 foi criado o Mestrado Profissional em Sustentabilidade junto a Povos e Terras Tradicionais, como uma nova área de concentração intitulada "Sustentabilidade junto a Povos e Terras Tradicionais" do Mestrado Profissional em Desenvolvimento Sustentável do Centro 
de Desenvolvimento Sustentável (CDS). Antes do Mestrado Profissional, o CDS ofereceu, em 2008, curso de Especialização em Indigenismo e Desenvolvimento Sustentável. (Http://www.mespt.unb.br/historico.html) 